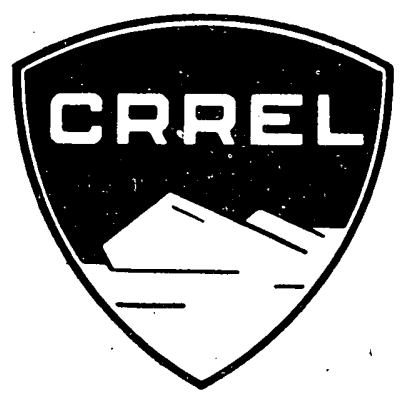

\title{
Research Report 229 \\ FORCES ON A SPHERE MOVING STEADILY ALONG A CIRCULAR PATH IN A VISCOUS FLUID
}

\author{
by \\ Fuat Odar
}

APRIL 1967

U.S. ARMY MATERIEL COMMAND

COLD REGIONS RESEARCH \& ENGINEERING LABORATORY

HANOVER, NEW HAMPSHIRE

DA Task IV014501B 52 AO2

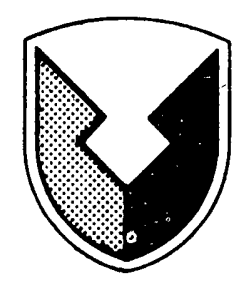




\section{PREFACE}

This paper was prepared by Dr. Fuat Odar, Research Civil Engineer, of the Physical Sciences Branch, Research Division (Mr. James A. Bender, Chief), U.S. Army Cold Regions Research and Engineering Laboratory.

The author appreciates helpful discussions with Dr. Y. C. Yen during the preparation of this paper and is grateful to Mr. R. E. Perham who helped design the apparatus. Sincere thanks are due to SP 4 D.P. Forgey for his invaluable assistance in conducting the experiments.

USA CRREL is an Army Materiel Command laboratory. 
Preface-1.2.

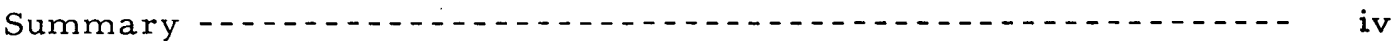

Introduction - - - -

Description of the apparatus

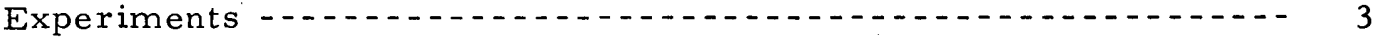

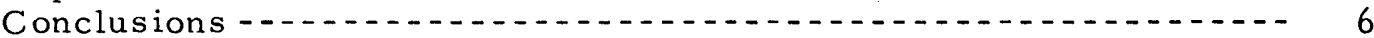

Figure

\section{ILLUSTRATIONS}

1. Sketch of the apparatus

2. Sphere assembly -

3. Drag coefficients in curved motion -....... 4

4. Variation of the normal drag coefficients with the Reynolds num-

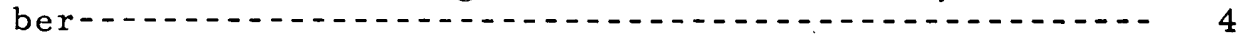

5. Streamlines around the sphere 


\section{SUMMARY}

Forces on a sphere moving steadily along a circular path in a viscous fluid are measured and it is found that within the experimental range both the longitudinal and normal forces are dependent on the Reynolds number and not on the radius of the path. Thus, the conventional drag coefficient can also be obtained from a rotational motion. 


\title{
FORCES ON A SPHERE MOVING STEADILY ALONG A CIRCULAR PATH IN A VISCOUS FLUID
}

\author{
by \\ Fuat Odar
}

\section{Introduction}

Recently many investigations on the motion of a sphere or an arbitrarily shaped body at low Reynolds numbers have been made. Most of them are theoretical and make use of asymptotic expansions. There seems to be some lack of experiments in this area of research. In this paper it is intended to fill a very small part of this gap in knowledge.

Brenner* showed that at very low Reynolds numbers the force on a sphere moving along a circular path is the same as the Stokes force. The experiments presented in this paper have Reynolds numbers ranging from about 6 to 185 . The findings suggest that this conclusion will also be valid for other Reynolds number values.

\section{Description of the apparatus}

The apparatus is shown in Figure 1. A 3-in. diam sphere is fastened to a blade immersed in a tank containing a viscous fluid and the forces and torque exerted by the fluid on the sphere are measured as the blade rotates in the vertical plane. The cross section of the blade is lenticular in order to minimize the disturbances in the fluid. The sphere can be relocated on the blade at any point up to 10 in. from the tip; thus, the radius of the path can be varied.

The speed of the motor which rotates the blade can be varied from $2.5 \mathrm{rpm}$ to $25 \mathrm{rpm}$. A large, perfectly balanced flywheel weighing about 1 ton was used to eliminate the torsional vibrations produced in the motor. Inside the tank, sleeves around the rotating shaft prevent it from disturbing the main body of fluid. A counterbalance balances the weight of the blade to reduce radial vibration of the shaft. Baffle discs almost completely eliminate the secondary radial flow produced during rotation. They come within 0.1 in. of the rotating blade and with the help of a rotating hoop between the discs (not shown on the figure) divert the radial flow back. The tank is $10 \mathrm{ft}$ high, $10 \mathrm{ft}$ long and $40 \mathrm{in}$. wide and the blade is 41 in. long; thus, the center of the sphere is always at least 20 in. from the boundary. During the experiments no boundary effect was detected.

The longitudinal force (F)- and torque $(T)$-measuring strain gage transducers are inside the sphere (Fig. 2). The normal force $\left(F_{N}\right)$-measuring strain gage transducer is located on the beam supporting the sphere. All gages are semi-conductors and have a gage factor of about 100. Since the forces during the experiment change with time due to the change in gravity and hydrostatic effects, it is necessary to damp the oscillations of the beams on which these gages are glued. Two dashpots containing silicone oil, one inside the sphere and the other along the supporting cantilever beam, were used to produce the proper damping. A mylar accordion seal at the back of the sphere seals both of the dashpots but does not hinder the deflections of the sphere or the supporting beam. Chambers inside the sphere reduce the difference between the gravity and buoyancy forces.

* Brenner, H (1963) The Stokes resistance of an arbitrary particle, Chemical Engineering Science, vol. 18, p. 1-25. 


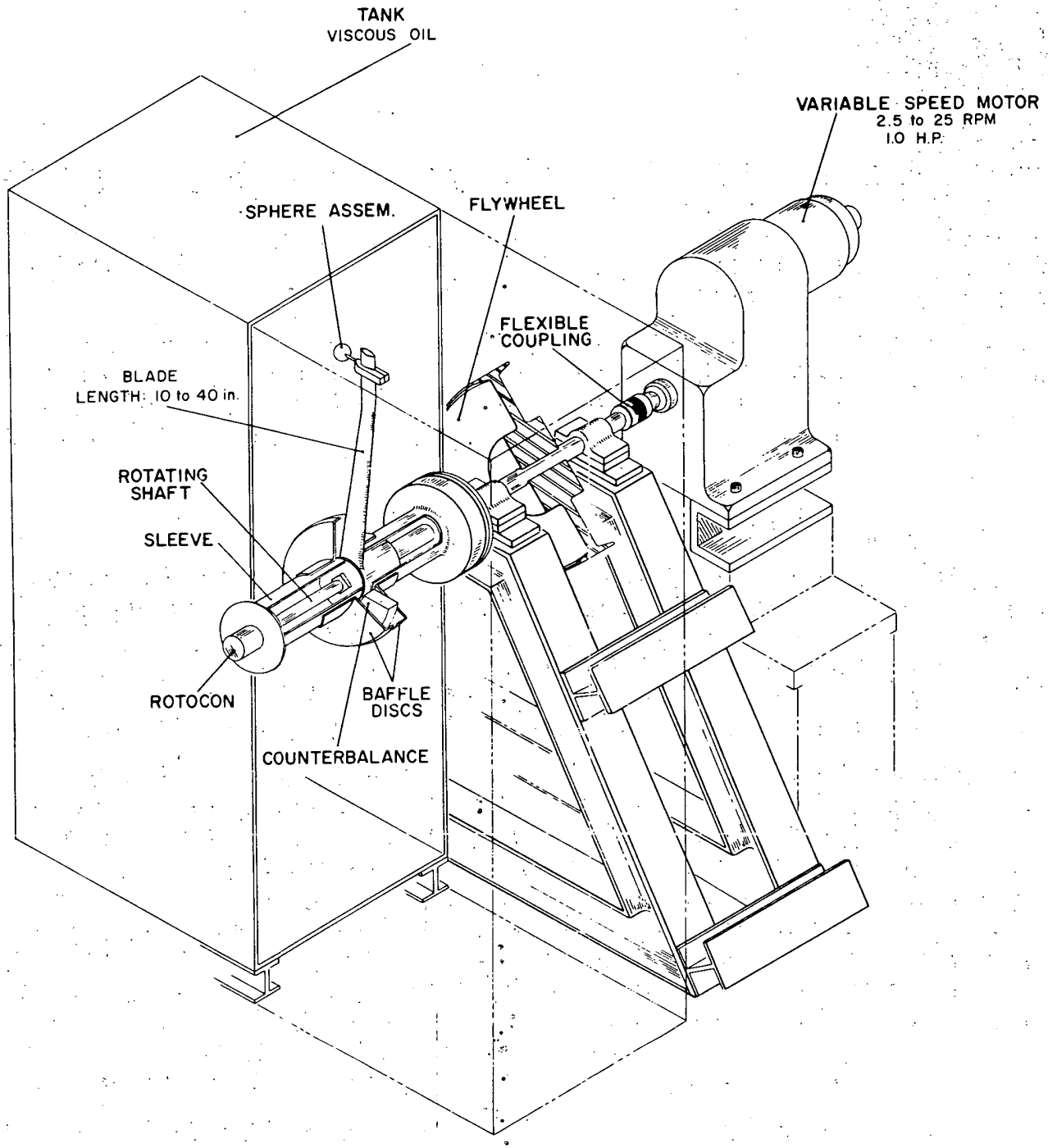

Figure 1. Sketch of the apparatus.

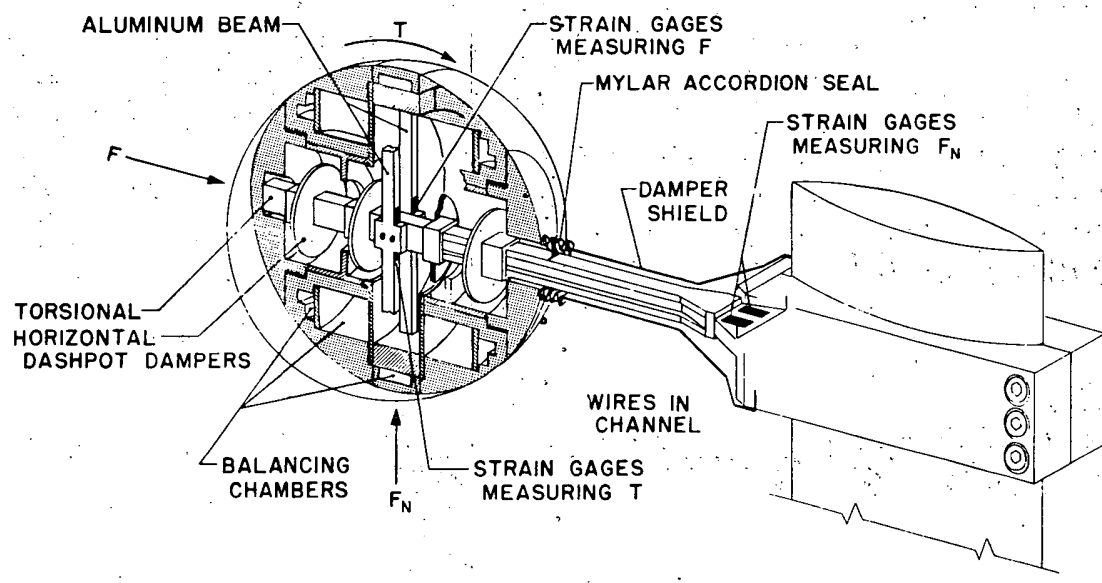

Figure 2. Sphere assembly. 
Due to the high gage factors and excellent, stable, low drift high gain amplifiers, the measuring system has a very high sensitivity. A blow of human breath produces about 0.2 in. deflection in the recording chart, a clearly visible and measurable quantity. The frequency response of the longitudinal force transducer is about $100 \mathrm{cps}$ which shows the ruggedness and the capability of high responsc to varying forces. The frequency response of the other transducers is about 40 cps which is still quite sufficient to measure satisfactorily the variations encountered in these experiments.

The floor of the building in which the apparatus is located vibrates at amplitudes of $5-10 \mu$ in. at various frequencies. It was found that these small vibrations caused large disturbances at the tip of the blade where the sphere is located and made measurements impossible. Mounting all components except the motor on a floating concrete block isolates the apparatus from these vibrations. The natural frequency of the system with the block is about $2 \mathrm{cps}$ and the system has excellent damping characteristics. The pressure in the mounting system which floats the block varies to bring the block back to its original horizontal position within $0.0005 \mathrm{in}$. after a weight is applied anywhere on the block. This makes it possible to keep the shaft horizontal and the blade vertical within close tolcrances.

Signals from the transducers are transmitted through wires located behind the blade and inside the shaft. At the end of the shaft the signals go through mercury baths in a device called a Rotocon (Fig. 1) which transmits them from rotating transducers to stationary amplifiers. Conventional brushes produce too much noise and therefore are not suitable for the transmission of low voltage signals.

\section{Experiments}

By using 21,31 and $41-$ in. blades, experiments were conducted for $10 \frac{1}{2}, 20 \frac{1}{3}$, $30 \frac{1}{2}$ and $40 \frac{1}{2}-$ in. path radii at different speeds. The viscosity and density of the fluid were $1.65 \times 10^{-2}$ slug/ft-sec and 1.725 slug/ft ${ }^{3}$ respectively. Using the conventional dragformula the values of the drag coefficients, $C_{D}$, were calculated for each run. Next the curve for the drag coefficient valid for uniform rectilinear motion was drawn and the calculated $C_{D}$ values were plotted for comparison (Fig. 3 ). It is evident that the radius of the path did not affect the value of the drag coefficient. The ratio of the sphere size to the smallest path radius is about 0.29 . Further experiments are needed to show whether or not this independence' still exists at smaller radii.

Many types of formulas were tested for an expression of the normal force, which is exerted by the fluid on the sphere outwards in the radial direction. Since the sphere accelerates toward the center, one might suspect that the added mass type formulas could have been used. However, analysis of the data shows that the normal force $F_{N}$ can be expressed as

$$
\mathrm{F}_{\mathrm{N}}=1 / 2 \mathrm{C}_{\mathrm{N}} \rho \mathrm{A} \mathrm{V}^{2}
$$

in which $\rho$ is the density of the fluid, $A$ is the projected area of the sphere and $V$ denotes its velocity. The coefficient $C_{N}$ is dimensionless and will be called the normal drag coefficient. The values of $C_{N}$ we re calculated for each run and it was found that $C_{N}$ was dependent on the Reynolds number as shown in Figure 4 . The values of $C_{N}$ for the $10 \frac{1}{2}$-in. path radius are somewhat higher than the others because it was impossible to use baffle discs with the $21-$ in. blade and therefore the secondary current could not be avoided. All other blades had appropriate baffle discs. To check their usefulness the baffle discs were removed from the $31-i n$. blade; higher values of normal force resulted. 


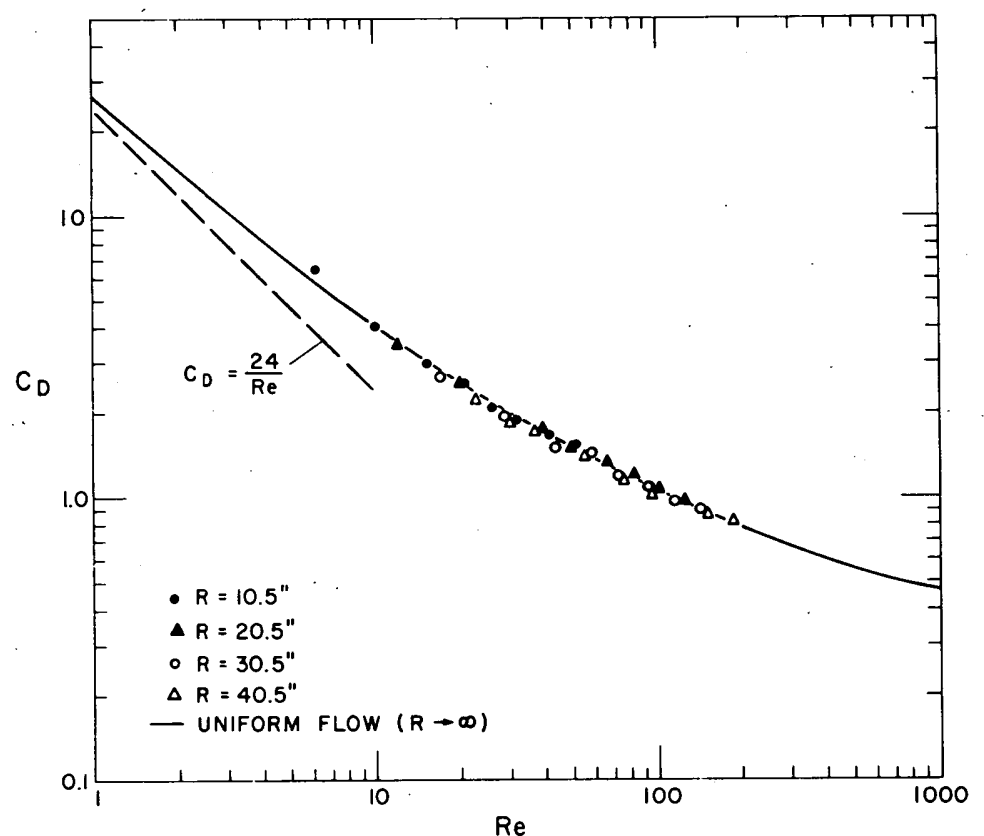

Figure 3. Drag coefficients in curved motion.

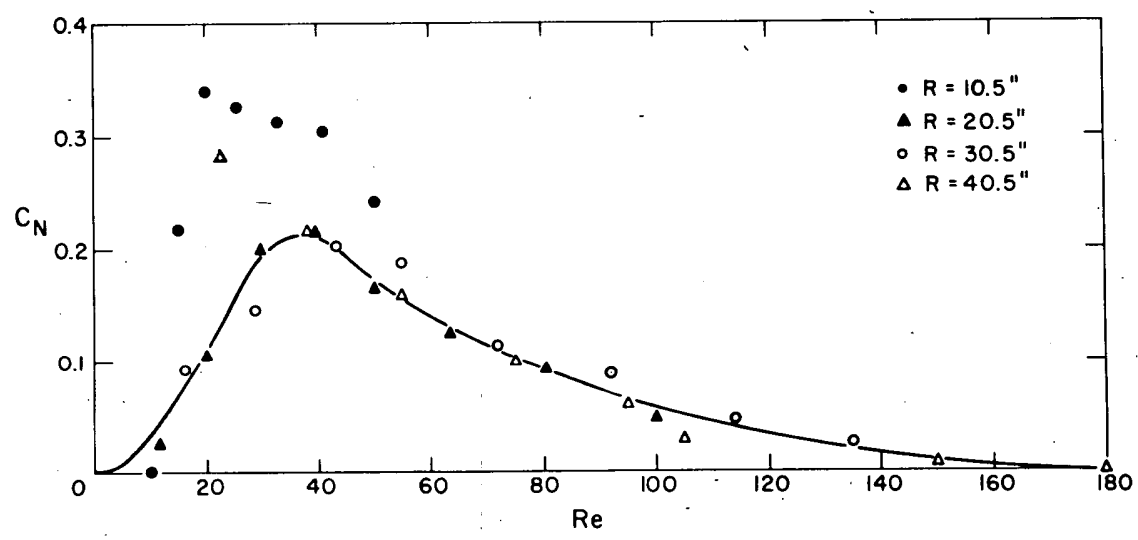

Figure 4. Variation of the normal drag coefficients with the Reynolds number.

The dependence of the normal force on the Reynolds number can be expected. Although the configuration of the streamlines is not exactly known, one can conjecture their disposition to a certain extent (Fig. 5). For simplicity a two-dimensional motion without any secondary flow in the vertical plane is imagined. The streamlines are those observed by an observer moving with the sphere. If we draw the streamlines in such a manner that the discharge between them remains the same, then the distance between streamlines a and b becomes less than that between $b$ and $c$. We can also expect that the stagnation point has moved in the direction of curvature. Thus, one can intuitively expect that streamline a is closer to the sphere than streamline $c$. This would cause a pressure difference acting radially outwards and also a difference in the local Reynolds number. 


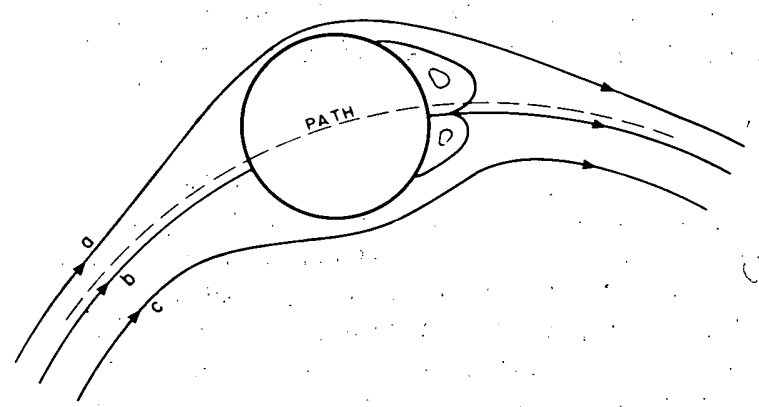

Figure 5. Streamlines around the sphere.
According to Jenson $*$ there is no separation behind a sphere below $\mathrm{Re}=$ 5 for uniform flow. It seems reasonable to assume that there will also be no separation in the rotational motion at a Reynolds number of the same order of magnitude. In a uniform flow at $\mathrm{Re}=$ 20 there is a small vortex behind the sphere and at $\mathrm{Re}=40$ the vortex becomes quite large. This is the region where experiments indicate that the values of $C_{N}$ are the highest. Evidently, in this Reynolds number region, due to the variation of the local Reynolds num-

bers, the separations do not occur at symmetrical locations. As the Reynolds number becomes large, the separations, vortices and streamlines tend to become symmetric around the sphere and, therefore, the normal force decreases.

From the picture of the streamlines it can be expected that the location of the stagnation point moves in the direction of curvature when the path radius becomes smaller. The movement of the stagnation point and increased asymmetry of the streamlines may cause a variation in the normal force and perhaps also in the longitudinal force. This would indicate that there must be some dependence of these quantities on the radius. The present experiments, with their limited range of radii, do not indicate any dependence of the normal force on the radius. Apparently in this range the variation of the radius does not appreciably alter the value of $\mathrm{C}_{\mathrm{N}}$. For larger radii the streamlines tend to become symmetric and the values of $\mathrm{C}_{\mathrm{N}}$ should become zero. For very small radii, if the inertia effects are negligible one can expect that $C_{N}$ will be zero; if the inertia effects become large there will be a dependence on the Reynolds number. As for the longitudinal force at very slow motion when the inertia effects are negligible, it is expected that Brenner's conclusion will still be valid even for very small radii. Although it is not obvious, there may be some dependence on the radius if radii are small and the inertia effects are large. If this is the case, as the radius becomes larger and larger this dependence will diminish and finally cease.

The torque exerted on the sphere was the most difficult quantity to measure since its magnitude was very small and the torque transducer was affected by the longitudinal and normal forces. It was not possible to get.consistent results. The torque transducer was wired in such a way that the effects of the longitudinal deflection due to the longitudinal force on each strain gage would cancel each other. However, the strain gages could not be located exactly symmetrically and it was also impossible to have the same thickness of glue under each strain gage. Furthermore, there was $1 \%$ variation in resistances of the gages according to the manufacturer's specifications. All these factors caused a cross effect, i.e., when the longitudinal force was applied there was a signal from the torque trans ducer. Since the longitudinal forces were so high the measurement of a small torque became very difficult. Furthermore, due to the electrical heating of the strain gages, the resistances were changing slightly. Although the changes were very small, this caused quite a variation in the cross effect since it was dependent on the difference in resistances of the gages. It seems that the proper location for the torque strain gages is on the supporting bar in the direction of the longitudinal force where the effect of the longitudinal force would be negligible. Although the results were inconsistent, they were useful to judge the effect of torque

*Jenson, V.G. (1959) Viscous flow around a sphere at low Reynolds numbers $(<40)$, Proceedings of the Royal Society (London), vol. A249, p. 346-366. 
on the normal force measurements. It was found that the amount of torque was generally very small; consequently it could be concluded that its effect on the normal force measurements was also small.

\section{Conclusions}

The path radius does not affect the longitudinal drag on the sphere, at least when the ratio of the sphere diameter to the path radius is higher than 0.29. This suggests that the longitudinal drag on a sphere moving irregularly at a constant speed but in a somewhat restricted manner, where this ratio is higher than 0.29 , is the same as that in a uniform flow. Although the experiments were made with a sphere, the findings also suggest that the same conclusion will be valid for differently shaped symmetrical objects where the ratio of a characteristic dimension to the path radius is higher than 0.29. Thus, one can readily determine the drag coefficients by using rotating motion instead of uniform flow.

The second important finding is that the normal force exerted by the fluid on the sphere is not very small between Reynolds numbers of 30 and 80 for the radii used in the experiments. In this region, $C_{N}$ is roughly $10 \%$ of $C_{D}$, which indicates that a freely moving sphere would tend to follow a straight path. This finding may be important in turbulent transport of solid particles since the particles will tend to move away from the vortices. 
Unclassified

Security Classification

\section{DOCUMENT CONTROL DATA - R\&D}

(Security classification of title, body of abstract and indexing annotation muat be entered when the overalt report is clasaified) 1. ORIGINATIN G ACTIVITY (Comporate author) 2a. REPORT SECURITY CLASSIFICATION Unclassified

U. S. Army Cold Regions Research and Engineering Laboratory, Hanover, N.H. 2b. GROUP

3. REPORT TITLE

FORCES ON A SPHERE MOVING STEADILY ALONG A CIRCULAR PATH IN A VISCOUS FLUID

4. DESCRIPTIVE NOTES (Type of report and inclusive dates)

Research Report

5. AUTHOR(S) (Last name, first name, initial)

Odar, Fuat

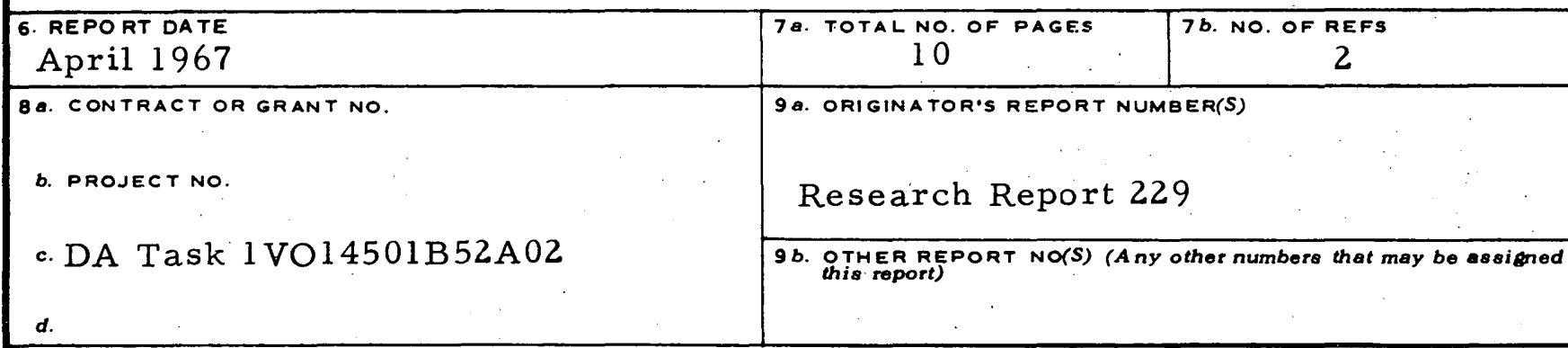

10. AVAILABILITY/LIMITATION NOTICES

Distribution of this document is unlimited

11. SUPPL EMENTARY NOTES

12. SPONSORING MILITARY ACTIVITY

U. S. Army Cold Regions Research and Engineering Laboratory

\section{ABSTRACT}

Forces on a sphere moving steadily along a circular path in a viscous fluid are measured and it is found that within the experimental range both the longitudinal and normal forces are dependent on the Reynolds number and not on the radius of the path. Thus, the conventional drag coefficient can also be obtained from a rotational motion. 


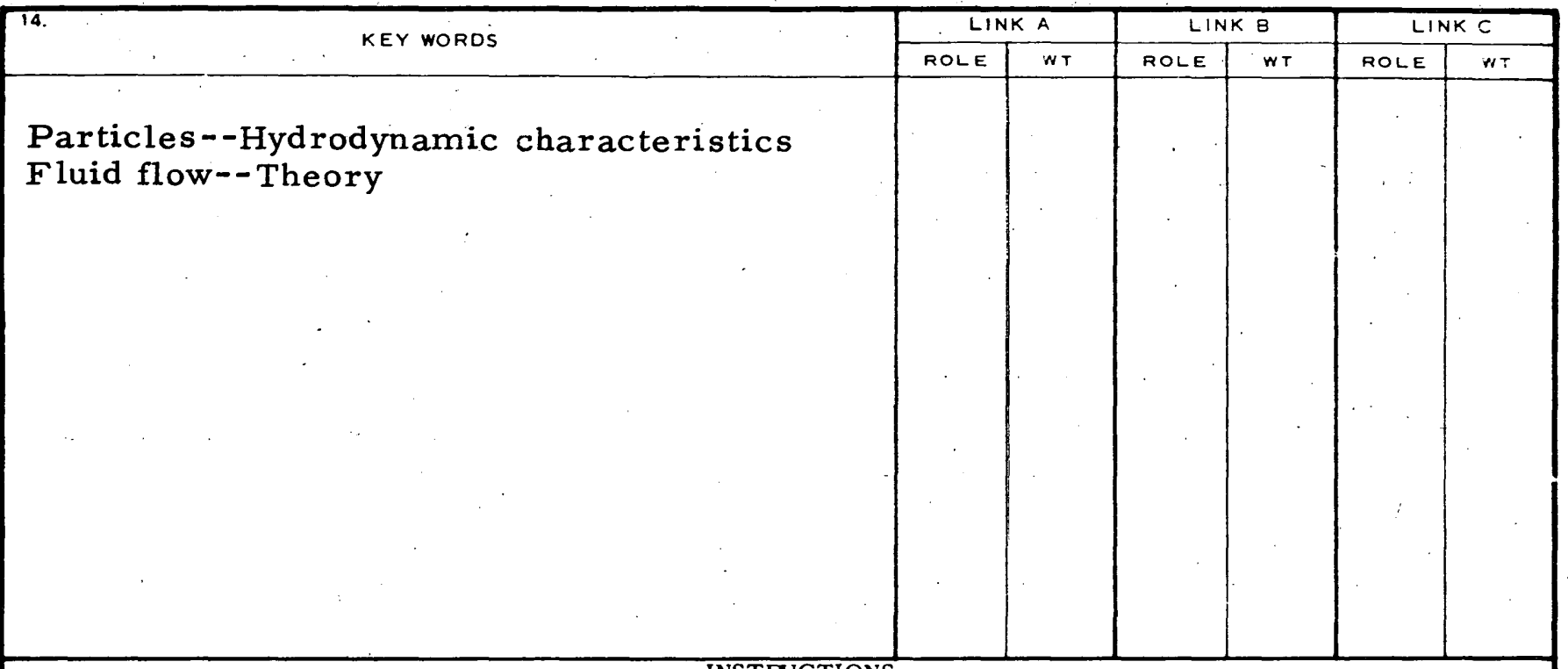

1. ORIGINATING ACTIVITY: Enter the name and address of the contractor, subcontractor, grantee, Department of Defense activity or other organization (corporate author) issuing the report.

2a. REPORT SECURTY CLASSIFICATION: Enter the overall security classification of the report. Indicate whether "Restricted Data" is included. Marking is to be in accordance with appropriate security regulations.

2b. GROUP: Automatic downgrading is specified in DoD Directive 5200.10 and Armed Forces Industrial Manual. Enter the group number. Also, when applicable, show that optional markings have been us ed for Group 3 and Group 4 as authorized.

3. REPORT TITLE: Enter the complete report title in all capital letters. Titles in all cases should be unclassified. If a meaningful title cannot be selected without classification, show title classification in all capitals in parenthesis immediately following the title.

4. DESCRIPTIVE NOTES: If appropriate, enter the type of report, e.g., interim, progress, summary, annual, or final.

Give the inclusive dates when a specific reporting period is covered.

5. AUTHOR(S): Enter the name(s) of author(s) as shown on or in the report. Enter last name, first name, middle initial. If military, show rank and branch of service. The name of the principal author is an absolute minimum requirement.

6. REPORT DATE: Enter the date of the report as day, month, year; or month, year. If more than one date appears on the report, use date of publication.

7a. TOTAL NUMBER OF PAGES: The total page count should follow normal pagination procedures, i.e., enter the number of pages containing information.

7b. NUMBER OF REFERENCES: Enter the total number of references cited in the report.

8a. CONTRACT OR GRANT NUMBER: If appropriate, enter the applicable number of the contract or grant under which the report was written.

$8 b, 8 c, 8 d 8$. PROJECT NUMBER: Enter the appropriate military department identific ation, such as project number, subproject number, system numbers, task number, etc.

9a. ORIGINATOR'S REPORT NUMBER(S): Enter the official report number by which the document will be identified and controlled by the originating activity. This number must be unique to this report.

9b. OTHER REPORT NUMBER(S): If the report has been assigned any other report numbers (either by the originator or by the sponsor), also enter this number(s).
10. AVALLABILITY/LIMITATION NOTICES: Enter any limitations on further dissemination of the report, other than those imposed by security classification, using standard statements such as:

(1) "Qualified requesters may obtain copies of this report from DDC."

(2) "Foreign announcement and dissemination of this report by DDC is not authorized."

(3) “U. S. Government agencies may obtain copies of this report directly from DDC. Other qualified DDC users shallirequest through ."

(4) "U. S. military agencies may obtain copies of this report directly from DDC. Other qualified users shall request through

$$
\therefore
$$

(5) "All distribution of this report is controlled. Qualified DDC users shall request through ."

If the'report has been furnished to the Office of Technical Services, Department of Commerce, for sale to the public, indicate this fact and enter the price, if known.

11. SUPPLEMENTARY NOTES:- Use for additional explanatory notes.

12. SPONSORING MILITARY ACTIVITY: Ent er the name of the departmental project of fice or laboratory sponsoring (paying $f o r)$ the research and development. Include address.

13. ABSTRACT: Enter an abstract giving a brief and factual summary of the document indicative of the report, even though it may also appear elsewhere in the body of the technical report. If additional space is required, a continuation sheet shall be attached.

It is highiy desirable that the abstract of classified reports be unclassified. Each paragraph of the abstract shall end with an indication of the military security classification of the information in the paragraph, represented as (TS), (S), (C), or $(U)$.

There is no limitation on the length of the abstract. However, the suggested length is from 150 to 225 words.

14. KEY WORDS: Key words are technically meaningful terms or short phrases that characterize a report and may be used as index entries for cataloging the report. Key words must be selected so that no security classification is required. Idenfiers, such as equipment model designation, trade name, military project code name, geographic location, may be used as key words but will be followed by an indication of technical context. The assignment of links, rules, and weights is optional. 